Article

\title{
Functional Features of Alginates Recovered from Himanthalia elongata Using Subcritical Water Extraction
}

\author{
Noelia Flórez-Fernández (D), Herminia Domínguez * and María Dolores Torres \\ Department of Chemical Engineering, Faculty of Sciences, University of Vigo, Edificio Politécnico, As Lagoas s/n, \\ 32004 Ourense, Spain; noelia.florez@uvigo.es (N.F.-F.); matorres@uvigo.es (M.D.T.) \\ * Correspondence: herminia@uvigo.es
}

check for updates

Citation: Flórez-Fernández, N.;

Domínguez, H.; Torres, M.D.

Functional Features of Alginates Recovered from Himanthalia elongata Using Subcritical Water Extraction. Molecules 2021, 26, 4726. https:// doi.org/10.3390/molecules26164726

Academic Editor: Benoît Chénais

Received: 5 July 2021

Accepted: 2 August 2021

Published: 4 August 2021

Publisher's Note: MDPI stays neutral with regard to jurisdictional claims in published maps and institutional affiliations.

Copyright: (c) 2021 by the authors. Licensee MDPI, Basel, Switzerland. This article is an open access article distributed under the terms and conditions of the Creative Commons Attribution (CC BY) license (https:// creativecommons.org/licenses/by/ $4.0 /)$.

\begin{abstract}
Subcritical water extraction of Himanthalia elongata and the subsequent acetone fractionation to precipitate crude fucoidans generated a liquid phase which was used to recover alginates with a wide range of viscoelastic features and other soluble extracts with potential biological activities. The precipitated alginate was converted to sodium alginate using an environmentally friendly treatment before being characterized by Fourier transform infrared attenuated total reflectance, nuclear magnetic resonance, high performance size exclusion chromatography and rheological measurements. The cell viability of three human cell lines (A549, HCT-116, T98G) in the presence of the extracts obtained before and after acetone fractionation was assessed. Fractionation with different acetone volumes showed a slight effect in the behavior of the different tested cell lines. Results also indicated a notable effect of the processing conditions on the block structure and molar mass of the extracted biopolymer, with the subsequent impact on the rheological properties of the corresponding gelled matrices.
\end{abstract}

Keywords: autohydrolysis; biopolymer; brown seaweed; antitumoral; rheology

\section{Introduction}

Seaweeds have been explored in the last decades. The biological properties associated with their compounds have been responsible for this increased interest [1]. The cell wall of the seaweeds contains, mainly, polysaccharides (fucoidan, alginate, agar, carrageenan, agarose and others) [2]. The colloids of the algae have a broad range of applications in different industries [3] such as food, pharmaceutic and cosmeceutical [4-7]. Furthermore, other bioactive compounds are present in the cell wall of the algae. In this context, development of an extraction strategy to obtain these compounds is necessary. Different technologies have been used to achieve this challenge, especially those focusing on ecofriendly processes using water as a solvent, a concept fitting in a sustainability approach [8]. Further fractionation steps as an acetone treatment modify the dielectric constant of water favoring the precipitation of sulfated polysaccharides, with the consequent impact on their structure and the corresponding functional properties [9].

Macroalgae metabolites have an important role because some of them can display positive effects on human health [10]. Anti-inflammatory, antitumoral, anticoagulant, antioxidant, anti-obesity and other biological properties have been associated with these macroalgae metabolites in recent research [5,11].

Asian countries have algae as part of their diet, and more recently, the consumption in other territories is increasing based on nutritional and biological properties. The edible brown seaweed Himanthalia elongata, widely known as "sea spaghetti", belongs to the order of Fucales [12]. As occurs with other brown seaweeds, composition is directly influenced by abiotic factors, and also the extraction process can impact the biological properties. Moreover, brown seaweeds have other polysaccharide with potential biological activities, mainly fucoidan and alginate [13-15]. Fucoidans are mostly comprised of fucose and sulfate groups, and other components, such as glucose, mannose, xylose and rhamnose are 
also present. The content and location of the sulfate groups affect the bioactive properties, which are highly dependent on the previous extraction and fractionation treatments [16].

Alginate is a biopolymer with suitable properties, such as biocompatibility, biodegradability and low toxicity, to be used for biomedical applications such as wound healing, drug delivery, tissue repair and regeneration $[7,17,18]$. This biopolymer is only present in brown seaweeds, providing algae flexibility and stability against marine currents. Furthermore, other properties are also associated with this biopolymer such as thickener, stabilizer or gelling agent with potential application in the industry. Alginate is comprised of mannuronic and guluronic acid units (Figure 1). According to their proportion, alginate can feature different molecular mass distributions and rheological properties in terms of viscosity, elasticity or thermal stability, which is critically relevant in order to define the potential final applications $[15,19]$.

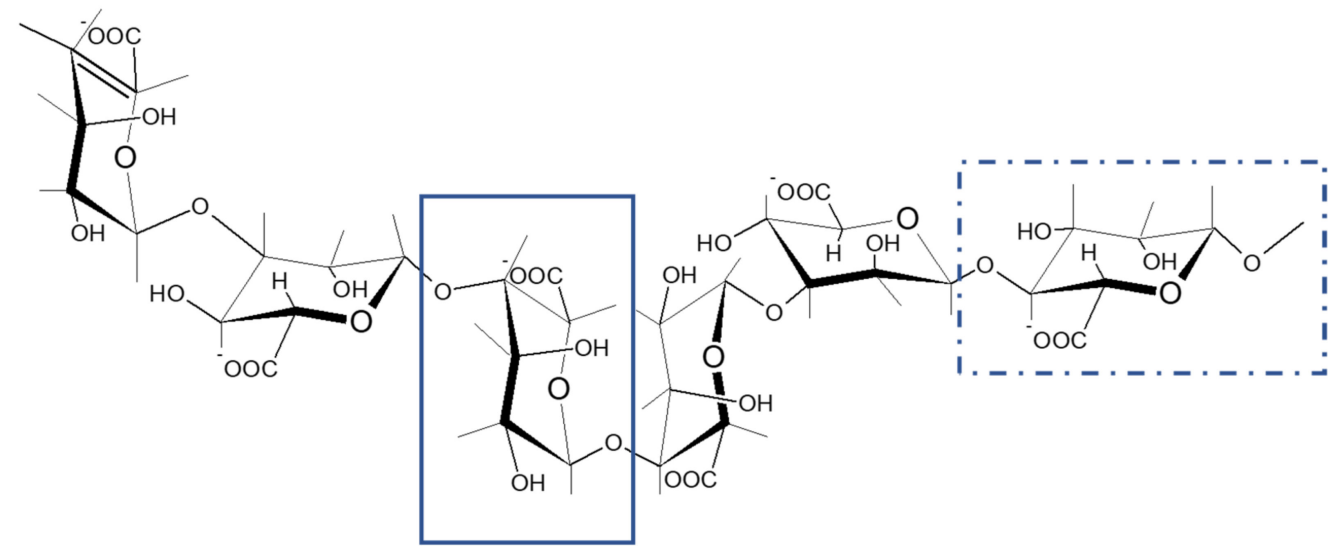

Figure 1. Structure of a possible configuration of alginate molecule. Guluronic acid is represented by a continuous line and mannuronic acid is represented by a dashed line.

Different studies have reported the biological activities of alginate as prebiotic, antitumor, anti-diabetic, anti-hypertensive, antimicrobial, immunomodulatory, anticoagulant or antioxidant, among others $[15,20]$. The antitumoral features of alginate have been reported from the point of view of the prevention of tumor cell proliferation. Nowadays, chemotherapy is a widely used treatment in cancer treatment, but some drugs (such as cisplatin) have limited use due to toxicity issues. In this context, marine sources (such as macroalgae) could have suitable properties to be used in biomedical applications [21].

The retrieving of high-value biomolecules from $H$. elongata using subcritical water extraction was previously proposed [22], but the influence of the process on the sodium alginate fraction was not assessed. The current work is focused on the structural and rheological characterization of sodium alginate obtained from this edible brown seaweed after subcritical water and acetone fractionation, and provides further insight on the biological potential of the recovered soluble extracts.

\section{Results and Discussion}

\subsection{General Overview}

One of the components of the brown seaweed is fucoidan, which is associated with different biological activities. Previous work by the authors of this study was focused on the extraction of this polysaccharide as well as assessment of its antioxidant and the cytotoxicity activities [22]. Furthermore, the behavior of the calcium alginate from the liquid phase of subcritical water extraction obtained at $160{ }^{\circ} \mathrm{C}$ was studied. It should be indicated that extracts recovered after hydrothermal process at the selected temperature were labelled as SWE, whereas those obtained after acetone fractionation were labelled as (SWE_A). Steady-shear flow curves and frequency sweeps of the dispersions prepared with the biopolymer extracted from the liquor of $H$. elongata were evaluated. The outcomes 
exhibited a similar behavior when compared with the commercial alginate, promoting an integral use of the edible H. elongata brown seaweed.

By analyzing the composition of $H$. elongata used here as raw material and reported in a previous work of these authors [22], it becomes evident that this edible alga is in consonance with others works where similar results were obtained [23,24]. Nevertheless, differences could be due to collection season, geographical location and abiotic factors [25]. Even then, brown seaweeds have some special biopolymers in their composition, such as alginate and fucoidan, which are both only present in brown algae, and both with an attractive potential in biomedical applications [14]. In this context, in the actual work metabolic activity was evaluated for the extracts obtained by SWE and, also, for the extracts obtained by acetone fractionation, increasing the behavior of the samples from H. elongata in several cell lines. Moreover, calcium alginate was converted to sodium alginate using a procedure previously reported [26], making this new biopolymer the main focus of the structural and rheological studies developed here (Figure 2).

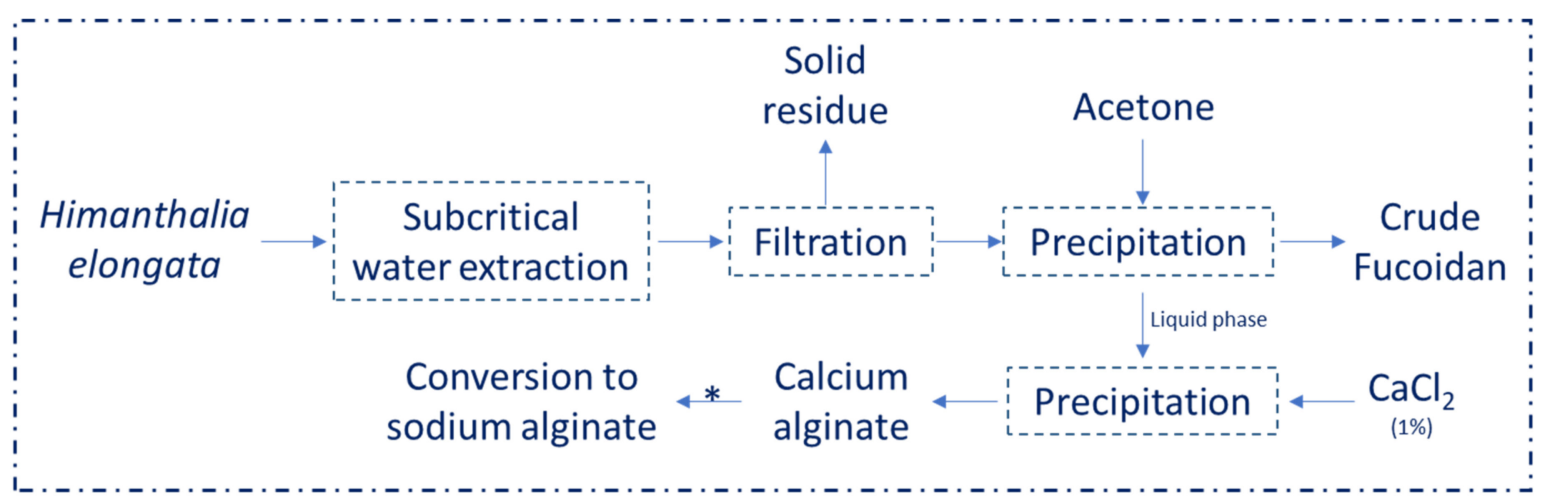

Figure 2. General overview of $H$. elongata extraction processing to the recovery of sodium alginate fraction. * The process to convert calcium in sodium alginate was previously reported in [26].

\subsection{Antiproliferative Action of Extracts}

Table 1 collects the study of the cell viability of the extracts obtained from $H$. elongata in tested human tumoral cell lines: epithelial lung adenocarcinoma (A549), colon carcinoma (HCT-116) and Caucasian human glioblastoma (T98G). The lowest cell viability was shown for the extract obtained at $160{ }^{\circ} \mathrm{C}$ using a concentration of $25 \mu \mathrm{g} / \mathrm{mL}$ with a value of approximately $44 \%$. In the previous work [22], lung (NCI-H460), ovarian (A2780) and breast (MCF-7) cell lines were assessed at $160{ }^{\circ} \mathrm{C}$ and $220^{\circ} \mathrm{C}$, the temperatures selected based on the maximum sulfate and phlorotannins content, respectively. It was reported that the cell inhibition was higher for lung and breast cell lines for the extract obtained at $220^{\circ} \mathrm{C}$. For the ovarian cell line, a slight increase of the inhibition was observed for the extract obtained at $160^{\circ} \mathrm{C}$ [22]. Taking into account the new data obtained in the present work, the observed behaviors could be partially explained by the fucose:sulfate ratio.

The cell viability of the extracts obtained after fractionation with different acetone volumes were evaluated, and different behavior was observed. The same concentration $(500 \mu \mathrm{g} / \mathrm{mL})$ and volume extraction $(0.5 \mathrm{v})$ showed two distinct values: $30.5 \%$ and close to $57 \%$ of cell viability for the cell lines HCT-116 and T98G, respectively. These tendencies can be related to the differences of the cell lines. A549 cell line, for the same acetone fractionation volume, at the concentration of $500 \mu \mathrm{g} / \mathrm{mL}$ led to a cell viability of $47.5 \%$, when the precipitation was performed with $1.5 \mathrm{v}$. 
Table 1. Influence on the cell viability of the extraction process on the extract obtained at $160{ }^{\circ} \mathrm{C}$ (SWE) and the acetone fractionation volumes (SWE_A) tested in three cell lines: A549 (epithelial lung adenocarcinoma), HCT-116 (colon carcinoma) and T98G (Caucasian human glioblastoma). Data represent mean $(n \geq 3) \pm S E M$.

\begin{tabular}{cccc}
\hline & \multicolumn{3}{c}{ Cell Viability (\%) } \\
\hline Cell Line & A549 & HCT-116 & T98G \\
\hline \multirow{2}{*}{ SWE } & $43.71 \pm 3.22$ & $50.86 \pm 1.02$ & $48.85 \pm 2.37$ \\
& $(25 \mu \mathrm{g} / \mathrm{mL})$ & $(25 \mu \mathrm{g} / \mathrm{mL})$ & $(25 \mu \mathrm{g} / \mathrm{mL})$ \\
\hline \multirow{2}{*}{ SWE_A } & $47.56 \pm 5.68$ & $30.50 \pm 4.70$ & $56.87 \pm 3.34$ \\
& $(500 \mu \mathrm{g} / \mathrm{mL})-1.5 \mathrm{v}$ & $(500 \mu \mathrm{g} / \mathrm{mL})-0.5 \mathrm{v}$ & $(500 \mu \mathrm{g} / \mathrm{mL})-0.5 \mathrm{v}$ \\
\hline
\end{tabular}

\subsection{Alginate}

The yield of sodium alginate recovered from liquid phases obtained during SWE treatment of $H$. elongata was around $5.9 \%$. The magnitude of this parameter increased with increasing the volume ratios of acetone:hydrolyzate from 0.5 to $2.0 v / v$, achieving values of $15.9 \%$. No notable differences were identified when 2.5 volumes of acetone were employed. This alginate extraction yield is in the range of that achieved for different alginophyte species using conventional extraction treatments, varying from around $3 \%$ to $40 \%$, such as Sargassum muticum (3\%), Sargassum turbinarioides (10\%), Sargassum asperifolium (12\%), Fucus guiryi $(13.6 \%)$, Fucus vesiculosus (16.2\%), Laminaria ochroleuca $(27.5 \%)$ or Lessonia nigrescens (34-41\%) [27]. It should be noted that the alginate content determined here is still higher than that previously found from other Fucales species (10\%) [28].

\subsubsection{Structural Properties}

Figure 3 presents the FTIR-ATR spectra of above sodium alginates obtained after acetone fractionation (from SWE_A0.5 to SWE_A2.5). Note here that the numbers after SWE_A correspond with the acetone volume ratio used for the fractionation. The spectrum of the sodium alginate recovered after subcritical water extraction at $160^{\circ} \mathrm{C}(\mathrm{SWE})$ is also displayed for comparative purposes. Similar profiles were identified in all cases, independently of the acetone ratio used. The major intensity signals, found at wavenumbers around $16001 / \mathrm{cm}$, were attributed to $\mathrm{O}-\mathrm{C}-\mathrm{O}$ and $\mathrm{C}=\mathrm{O}$ asymmetric stretching vibrations of uronic acids; the bands at $14101 / \mathrm{cm}$ corresponded to $\mathrm{C}-\mathrm{OH}$ deformation vibration [29]. The peaks at $12401 / \mathrm{cm}$, attributed to the existence of sulfate groups, were stronger for alginates recovered after acetone fractionation (SWE_A0.5-SWE_A2.5). The signals around $10201 / \mathrm{cm}$, related to the C-O polysaccharides vibrations, were of intermediate intensity for all tested sodium alginates. Bands of minor intensity identified at $8901 / \mathrm{cm}$ were assigned to the $\alpha$-L-guluronic asymmetric ring vibration, and at $8201 / \mathrm{cm}$ to the $\beta$-mannuronic acid. These spectra are consistent with those previously reported for extracts from H. elongata using conventional Soxhlet extraction [30]. It should be remarked that FTIR-ATR spectra of alginates from previous studies of other Fucales species extracted with different methods (water, acid, enzymatic extraction) did not show relevant differences either [31]. 


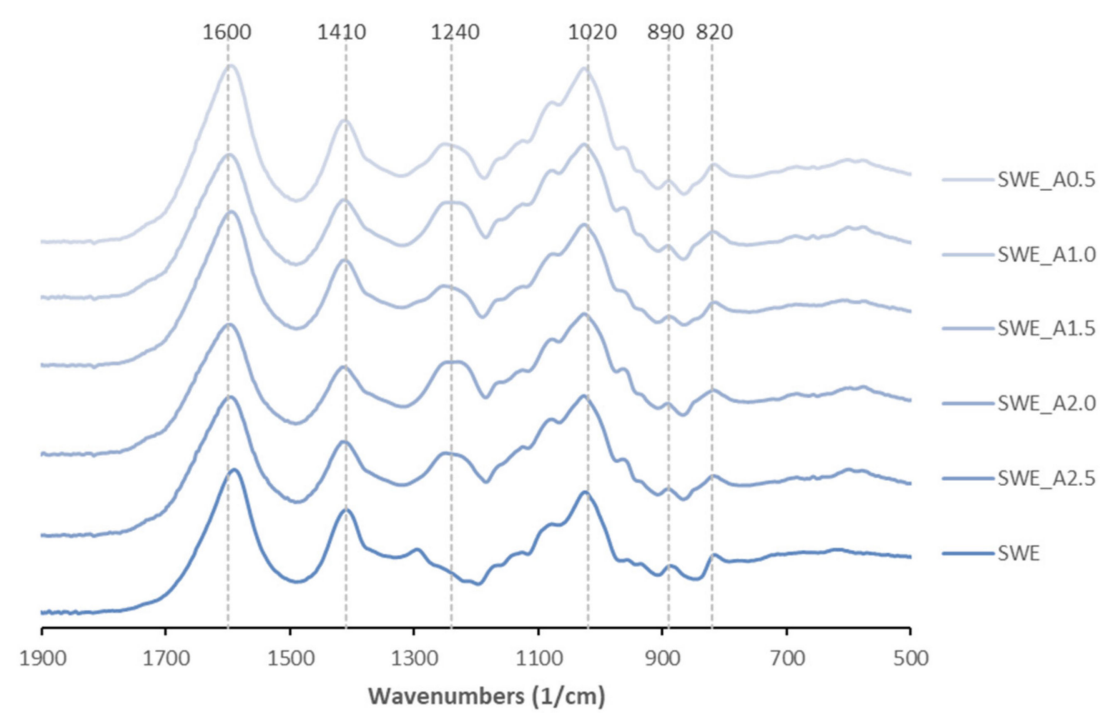

Figure 3. FTIR-ATR profiles of sodium alginate extracted from $H$. elongata after subcritical water extraction (up to $160^{\circ} \mathrm{C}$ ) followed by acetone fractionation (SWE_A0.5-SWE_A2.5) using 0.5-2.5 acetone:liquid extract volume ratio, $v / v$.

Table 2 summarizes the compositional block structural features of the above sodium alginates obtained from ${ }^{1} \mathrm{HNMR}$ spectra. The well-known characteristic signals identified in the spectra (i.e., guluronic acid anomeric proton (about $5.2 \mathrm{ppm}$ ), guluronic acid (about $4.6 \mathrm{ppm}$ ), mannuronic acid anomeric proton (about $4.8 \mathrm{ppm}$ ) and the alternating blocks (about $4.9 \mathrm{ppm}$ ) together with the corresponding areas were employed for the quantitative assessment of the guluronic and mannuronic acids $\left(F_{G}, F_{M}\right), M / G$ ratios and diad frequencies $\left(\mathrm{F}_{\mathrm{GG}}, \mathrm{F}_{\mathrm{MM}}, \mathrm{F}_{\mathrm{GM}}, \mathrm{F}_{\mathrm{MG}}\right)$ [32].

Table 2. Impact of the acetone fractionation on the sodium alginate fractions extracted from H. elongata.

\begin{tabular}{lcccccc}
\hline Alginate & $\mathbf{M} / \mathbf{G}$ & $\mathbf{F}_{\mathbf{M}}$ & $\mathbf{F}_{\mathbf{G}}$ & $\mathbf{F}_{\mathbf{M M}}$ & $\mathbf{F}_{\mathbf{G G}}$ & $\mathbf{F}_{\mathbf{M G}}=\mathbf{F}_{\mathbf{G M}}$ \\
\hline SWE & $1.94^{\mathrm{a}}$ & $0.66^{\mathrm{a}}$ & $0.34^{\mathrm{e}}$ & $0.58^{\mathrm{a}}$ & $0.26^{\mathrm{a}}$ & $0.08^{\mathrm{e}}$ \\
SWE_A0.5 & $1.78^{\mathrm{b}}$ & $0.64^{\mathrm{b}}$ & $0.36^{\mathrm{d}}$ & $0.54^{\mathrm{b}}$ & $0.26^{\mathrm{a}}$ & $0.10^{\mathrm{d}}$ \\
SWE_A1.0 & $1.56^{\mathrm{c}}$ & $0.61^{\mathrm{c}}$ & $0.39^{\mathrm{c}}$ & $0.48^{\mathrm{c}}$ & $0.26^{\mathrm{a}}$ & $0.13^{\mathrm{c}}$ \\
SWE_A1.5 & $1.44^{\mathrm{d}}$ & $0.59^{\mathrm{d}}$ & $0.41^{\mathrm{b}}$ & $0.44^{\mathrm{d}}$ & $0.26^{\mathrm{a}}$ & $0.15^{\mathrm{b}}$ \\
SWE_A2.0 & $1.27^{\mathrm{e}}$ & $0.56^{\mathrm{e}}$ & $0.44^{\mathrm{a}}$ & $0.38^{\mathrm{e}}$ & $0.26^{\mathrm{a}}$ & $0.18^{\mathrm{a}}$ \\
SWE_A2.5 & $1.27^{\mathrm{e}}$ & $0.56^{\mathrm{e}}$ & $0.44^{\mathrm{a}}$ & $0.38^{\mathrm{e}}$ & $0.26^{\mathrm{a}}$ & $0.18^{\mathrm{a}}$ \\
\hline
\end{tabular}

In all cases, standard deviations were $<0.01$. Data values in a column with different superscript letters are significantly different at the $p \leq 0.05$ level.

Acetone fractionation involved a clear impact on $F_{M}, F_{G}$ and the corresponding $M / G$ ratios of tested sodium alginates. Not only was a clear increase of $F_{G}$ with acetone increase observed, but also a significant drop of $\mathrm{F}_{\mathrm{M}}$ and $\mathrm{M} / \mathrm{G}$. The magnitude of this latter parameter indicated higher values of mannuronic than guluronic acid blocks. This behavior $(M / G>1)$ is consistent with the results previously reported for alginates from Himanthalia elongata [33] as well as other Fucales species, such as Sargassum muticum (1.04), Sargassum vulgare (1.27) or Fucus vesiculosus (1.44-1.84) [27]. It should be remarked that M/G ratio magnitude can provide relevant insight to define the alginate final application. Those biopolymers with lower $\mathrm{G}$ content usually provide lower viscosity and higher flexibility, being attractive to develop nanoparticles or polyelectrolyte complexes, whereas those with low $\mathrm{M}$ content usually feature higher viscosity, being adequate to formulate gelled matrices for food and non-food applications [26]. However, it is necessary to take into account not only the effect of the homopolymeric block structures, but also the alternating blocks. Intermediate $\mathrm{F}_{\mathrm{MM}}$ as well as low $\mathrm{F}_{\mathrm{GG}}$ and alternating blocks $\left(\mathrm{F}_{\mathrm{MG}}=\mathrm{F}_{\mathrm{GM}}\right)$ favored the gelling capability of these alginates [28]. Overall, SWE and the subsequent acetone fractionation had a remarked impact on the alginate structure and in their mechanical potential. 
Figure 4 shows the corresponding HPSEC profiles of the sodium alginates recovered from $H$. elongata after acetone fractionation. An increase in the depolymerization of the sodium alginate was observed with increasing acetone content up to SWE_A2.0, without notable differences with SWE_A2.5. The major peaks corresponding to the highest molecular mass displayed a progressive increase with acetone ratio, between 12,000-25,000 g/mol. The compounds with the molecular weight (around $1000 \mathrm{~g} / \mathrm{mol}$ ) increased with acetone ratio $1.0 \mathrm{v}$ and $1.5 \mathrm{v}$ and decreased at $2.0 \mathrm{v}$ and $2.5 \mathrm{v}$. It was observed that both, increase and decrease, allowed similar levels as in the original extract (SWE). The figure shows a clear impact on the molecular weight distribution related to the acetone ratio used. A relevant effect on this parameter of other biopolymers as fucoidans was previously reported for the acetone fractionation of the liquid phases at the same temperature gathered from $H$. elongata [22]. The latter work showed that the highest fucoidan fraction of the liquid phases was found at about $5 \mathrm{kDa}$, and was shifted to $25 \mathrm{kDa}$ in the presence of the highest acetone values. It was also observed that sodium alginates with the average lowest molecular mass presented the highest $\mathrm{M} / \mathrm{G}$ ratios. In this context, the areas of the peaks corresponding with dextrans $>12,000 \mathrm{~g} / \mathrm{mol}$ follow the trend acetone ratio $2.5>2.0>1.5>1.0>0.5$, which is consistent with the $\mathrm{M} / \mathrm{G}$ ratios behavior, consistently with the outcomes previously reported for other Fucales species [34]. A certain degree of depolymerization of sodium alginate has been found after other purification treatments that could be taken advantage of to obtain fluids with lower viscosity values [35]. Despite that high molecular mass alginates can exhibit stronger gelling features, a distribution with low molecular masses is necessary to control the high viscosity properties favoring the industrial processing.

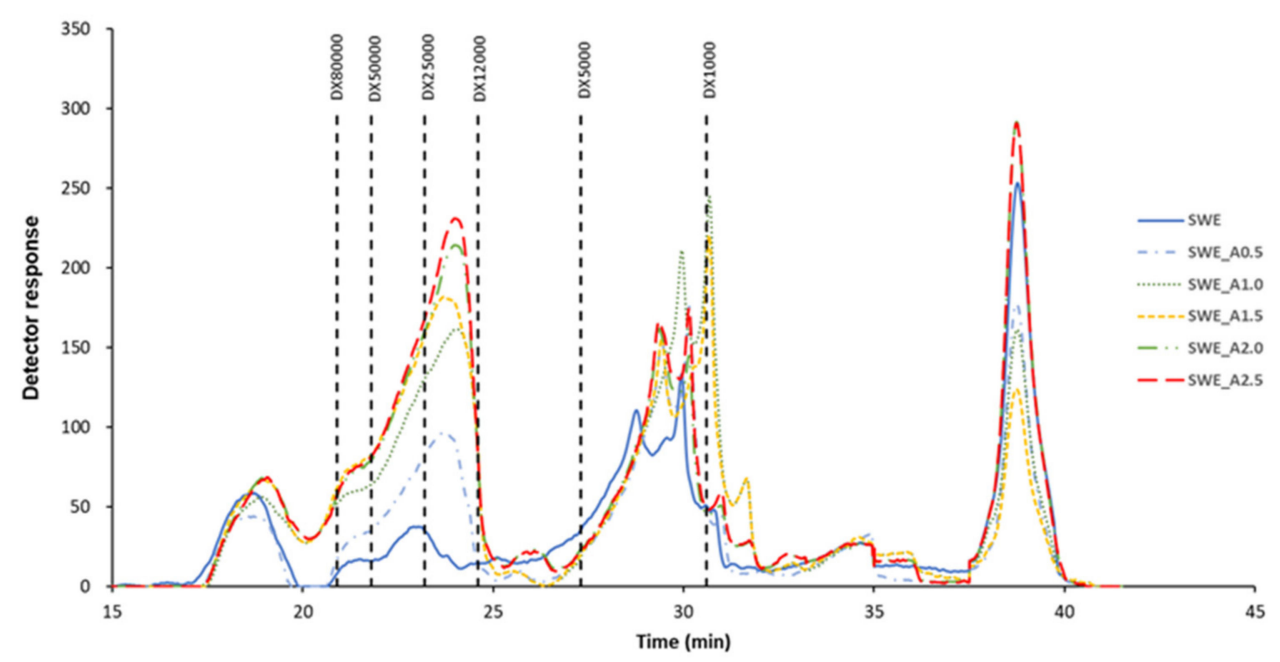

Figure 4. HPSEC profiles of sodium alginate extracted from $H$. elongata after representative subcritical water extraction $\left(160{ }^{\circ} \mathrm{C}\right)$ followed by acetone fractionation $(0.5-2.5$ acetone:liquid extract volume ratio, $v / v)$.

\subsubsection{Thermo-Rheological Properties}

Figure 5 displays the effect of acetone fractionation on the thermo-rheological properties of matrices formulated with the corresponding sodium alginates made in $\mathrm{CaCl}_{2}$ at $20^{\circ} \mathrm{C}$. A characteristic gel behavior can be observed for all matrices (i.e., $G^{\prime}>G^{\prime \prime}$, both moduli almost frequency independent). Note here that $G^{\prime}$ exhibited values around 10-times larger than $G^{\prime \prime}$ over the tested frequency range. A clear impact of the acetone fractionation of tested sodium alginates was identified in the developed gelled matrices, since both moduli increased at a fixed frequency with acetone increasing up to SWE_A2.0. Again, no notable differences were noticed for SWE_A2.5. These tendencies are consistent with those previously described for alginate structural blocks and molecular mass distributions as sodium alginates with the highest molecular mass as well as the lowest $\mathrm{M}$ content and consequently M/G ratios (SWE_A2.0, SWE_A2.5) led to the development of the gels with the highest viscoelastic features. The low magnitude of $\mathrm{F}_{\mathrm{MG}}=\mathrm{F}_{\mathrm{GM}}$ blocks also promoted 
the gel formation, as previously reported for other Fucales species [26]. According to the $G^{\prime}$ and $G^{\prime \prime}$ moduli values, intermediate gels strengths were obtained in all cases. Despite this fact, all gelled matrices exhibited viscoelastic magnitudes within those found in commercial foodstuff as gelling desserts [36].

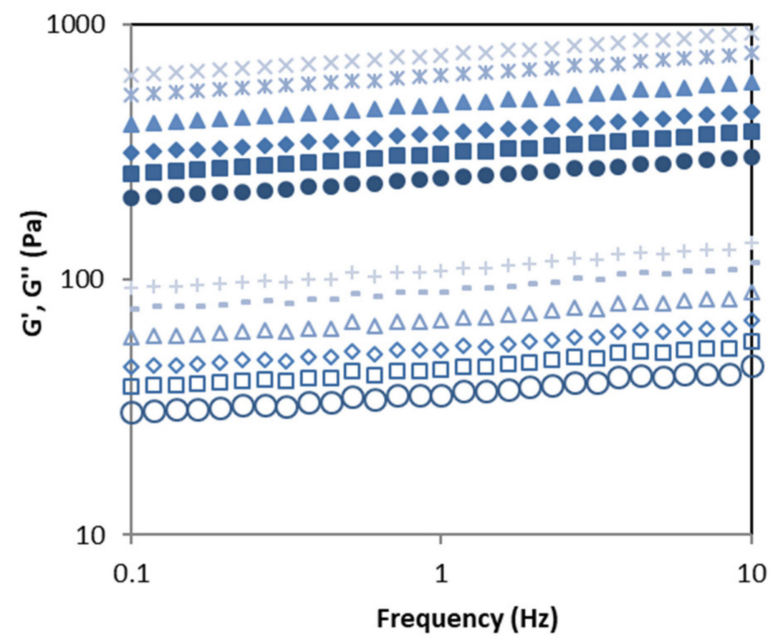

Figure 5. Frequency sweeps of gelled matrices made with sodium alginate extracted from H. elongata after representative subcritical water extraction $\left(160{ }^{\circ} \mathrm{C}\right)$ followed by acetone fractionation (0.5-2.5 acetone:hydrolyzed, $v / v)$. Symbols: $\mathrm{G}^{\prime}$, closed symbols; $\mathrm{G}^{\prime \prime}$, open symbols, circles (SWE), squares (SWE_A0.5), diamonds (SWE_A1.0), triangles (SWE_A1.5), double blades (G', SWE_A2.0), blades ( $G^{\prime}$, SWE_A2.5), crosses ( $G^{\prime \prime}$, SWE_A0.5), lines ( $G^{\prime \prime}$, SWE_A0.5).

The influence of acetone fractionation on the thermal features of recovered sodium alginates is presented in Figure 6. Temperature ramps of gelled matrices showed predominant elastic behavior (about 10-times). In heating ramps, $G^{\prime}$ and $G^{\prime \prime}$ moduli decreased with increasing temperature over the tested temperature range. While assessing the behavior at a fixed temperature, it was observed that both viscoelastic moduli increased with increasing acetone content used during the fractionation step. Similar tendencies were observed for the corresponding cooling sweeps. Note here that a quick stability step was identified for tested alginates $(<2.5 \mathrm{~min})$ determined in the performed time sweeps, which is an indication of the mechanical stability of tested alginates with the consequent industrial relevance. These results agree with those previously reported for gelled matrices prepared with ultrasound treated alginates from other Fucales species [26]. No gelling/melting temperatures were identified in the tested cooling/heating assays within the studied temperature range. The frequency sweeps performed after thermal analysis did not show notable differences with those presented in Figure 5, suggesting strong thermo-reversible features of the studied sodium alginate. Finally, it should also be remarked that no water syneresis was identified for gelled matrices formulated with sodium alginates recovered after acetone fractionation of SWE liquid phases of H. elongata for two weeks of cold storage. 


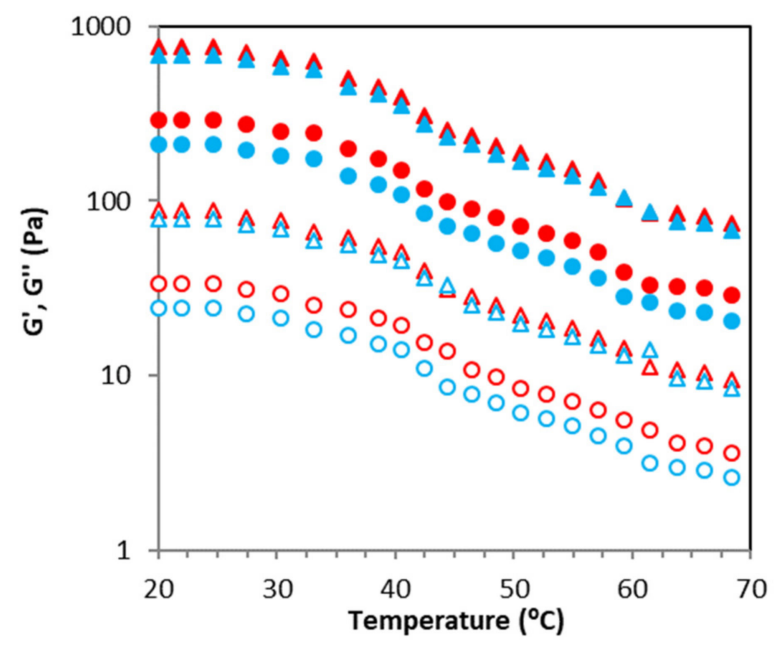

Figure 6. Representative thermal heating (red symbols) and cooling (blue symbols) profiles of tested systems. Symbols: $G^{\prime}$, closed symbols; $G^{\prime \prime}$, open symbols, circles (SWE), triangles (SWE_A2.0).

\section{Materials and Methods}

\subsection{Raw Materials}

Dehydrated Himanthalia elongata was purchased to Algas Atlanticas Algamar S.L. (Pontevedra, Spain). The industrial processing of these seaweeds comprised a fresh cleaning stage, followed by drying at $42{ }^{\circ} \mathrm{C}$ in a convective oven. After reception, the seaweeds were ground and stored in darkness at room temperature in opaque plastic bags until further use.

\subsection{Extraction Treatment}

Subcritical water extraction (SWE) was performed under non isothermal conditions up to the maximal heating temperature to obtain soluble extracts from the brown seaweed $H$. elongata, according to a previous work [22]. Briefly, the extraction treatment was performed in a pressurized reactor with continuous stirring (Parr Instruments series 4842, USA) using a ratio of 1:30 $(w / w)$ alga:water, the temperature increase up to the selected temperature $\left(160^{\circ} \mathrm{C}\right)$ and then the reactor was quickly cooled down to room temperature. Liquid and solid phases were separated by vacuum filtration.

Acetone fractionation was used to precipitate oligosaccharides from the liquid phase, and the acetone:liquid extract volume ratios were observed to influence the recovery yields [22]. Briefly, the volume ratios were increased from 0.5 to $2.0(v / v)$, mixed and kept at $4{ }^{\circ} \mathrm{C}$ for $24 \mathrm{~h}$. Then, they were separated by centrifugation for further analysis.

\subsection{Alginate Fraction}

Alginate was precipitated with $\mathrm{CaCl}_{2}(1 \% w / w)$ from the liquid fractions obtained after acetone fractionation. The appropriate amount of the above salt was added to the liquid phase and stirred for $4 \mathrm{~h}$ before overnight cold storage. Then, in order to separate the calcium alginate, systems were centrifuged (15 min, $4000 \mathrm{rpm}$ ). According to a greener approach for the conversion to sodium alginate comprehensively detailed in a previous work [26], the calcium biopolymer was carefully treated. Briefly, hydrochloric acid commonly used in the well-known conventional procedure was substituted by lemon juice (up to $\mathrm{pH} 3$ ); and sodium carbonate was added to get the alginic acid sodium salt. Afterwards, this biopolymer was dried in a vacuum oven $\left(-0.8 \mathrm{bar}, 40^{\circ} \mathrm{C}, 48 \mathrm{~h}\right)$.

\subsubsection{Fourier Transform Infrared Attenuated Total Reflectance (FTIR-ATR)}

FTIR-ATR tests of the above dried sodium alginates $(2 \mathrm{mg})$ were conducted on a Nicolet 6700 (Thermo Scientific Infrared Spectrophotometer, USA) equipped with a deuteratedtriglycine sulfate detector (DGTS). Samples were blended with $\mathrm{KBr}(10 \mathrm{mg})$, pressed at 7 ton 
and dried using an infrared lamp (30 min). FTIR-ATR spectra were recorded (400-4000 nm, $32 \mathrm{scan} / \mathrm{min}$ ) using the OPUS-2.52 software (Opus Software Limited, Grantham, UK).

\subsubsection{Proton Nuclear Magnetic Resonance ( ${ }^{1} \mathrm{H}$ NMR)}

${ }^{1} \mathrm{H}$ NMR spectra of above sodium alginates were monitored on a Bruker ARX400 (Bruker BioSpin GmbH spectrometer, Steuerberater, Germany). Measurements of the biopolymers solutions $(10 \mathrm{mg} / \mathrm{mL})$ were made using deuterated water as a solvent, 3(trimethylsilyl)-L-propane sulfonic acid (Sigma-Aldrich, St. Louis, MO, USA) as an internal standard, and operated at $400 \mathrm{MHz}$ and $75{ }^{\circ} \mathrm{C}$. Note here that ${ }^{1} \mathrm{H}$ NMR signals corresponding to the anomeric protons of the mannuronic $(\mathrm{M})$ and guluronic $(\mathrm{G})$ acids were reported elsewhere at 4.70 and $5.08 \mathrm{ppm}$, respectively. Moreover, the $\mathrm{M} / \mathrm{G}$ ratio was calculated according to the procedure previously described [26].

\subsubsection{High Performance Size Exclusion Chromatography (HPSEC)}

HPSEC chromatograms of tested alginates and SWE were performed in a 1260 series Hewlett-Packard chromatograph (Agilent, Waldbornn, Germany) with a refractive index detector. The sample was injected with autosampler and the volume was $5 \mu \mathrm{L}$. Two columns $300 \times 7.8 \mathrm{~mm}$ (TSKGel G2500PW $\mathrm{XL}_{\mathrm{L}}$ and TSKGel G3000PW $\mathrm{XL}_{\mathrm{L}}$, Tosoh Bioscience, Zürich, Germany) in series and one $40 \times 6 \mathrm{~mm}$ PWX-guard column were used as measuring systems. Measurements were run using Milli $\mathrm{Q}$ water $(0.4 \mathrm{~mL} / \mathrm{min})$ as mobile phase and dextrans (1000-80,000 g/mol) (Fluka, St. Louis, MO, USA) as calibration standards. The corresponding molar mass distribution chromatograms were recorded using the ChemStation for LC systems software (Agilent Technology, Germany).

\subsubsection{Rheology}

Sodium alginate was dispersed in distilled water at a usually employed biopolymer content $(1.0 \mathrm{~g} / \mathrm{L})$ and room temperature. It should be remarked that $\mathrm{CaCl}_{2}(0.1 \mathrm{~mol} / \mathrm{L})$ was used as a gelling agent according to the method reported elsewhere [26].

Monitoring of the viscoelastic behavior of the sodium alginate gelled matrices was carried out through small amplitude oscillatory shear testing in a MCR302 rheometer (Anton Paar, Austria, Germany). Gelled biopolymer based systems were placed on the sand blasted plate-plate measuring system (1 mm gap, $25 \mathrm{~mm}$ diameter). Light paraffin oil was employed to seal the sample edges in order to prevent water release during rheological testing. All systems were rested for $10 \mathrm{~min}$ to allow thermal and structural equilibration prior to the experiments. Firstly, stress sweeps $\left(20\right.$ and $\left.70{ }^{\circ} \mathrm{C}, 1 \mathrm{~Hz}\right)$ were performed to define the linear viscoelastic region $(<72 \mathrm{~Pa})$ for the alginate gelled matrices. Then, the rheology study consisted of a 6-step procedure: (1) frequency sweep $\left(20^{\circ} \mathrm{C}, 20 \mathrm{~Pa}\right)$ to define the viscoelastic gel characteristics (i.e., elastic, $\mathrm{G}^{\prime}$, and viscous, $\mathrm{G}^{\prime \prime}$, moduli), (2) heating thermal sweep up to $70{ }^{\circ} \mathrm{C}\left(1{ }^{\circ} \mathrm{C} / \mathrm{min}, 20 \mathrm{~Pa}, 1 \mathrm{~Hz}\right)$, (3) time sweep $\left(70{ }^{\circ} \mathrm{C}, 15 \mathrm{~min}, 20 \mathrm{~Pa}\right.$, $1 \mathrm{~Hz}),(4)$ cooling thermal sweep to $20^{\circ} \mathrm{C}\left(1{ }^{\circ} \mathrm{C} / \mathrm{min}, 20 \mathrm{~Pa}, 1 \mathrm{~Hz}\right)$, (5) time sweep $\left(20^{\circ} \mathrm{C}\right.$, $15 \mathrm{~min}, 20 \mathrm{~Pa}, 1 \mathrm{~Hz}$ ) and (6) frequency sweeps (same conditions as in step 1). Steps 2 to 6 allow evaluation of the thermal stability of the sodium alginates.

\subsubsection{Syneresis of the Gelled Matrices}

The water syneresis of the above gelled matrices was also evaluated following the experimental method described in detail by [37]. Briefly, gels were stored in centrifuge tubes in the fridge for two weeks. Afterwards, gelled matrices were centrifuged at $2000 \mathrm{~g}$ for $20 \mathrm{~min}$, and the syneresis estimated as the percentage between the water release and the weight of the gelled matrices.

\subsection{Antitumoral Features of the Extracts}

The cell viability of the extracts obtained by subcritical water extraction and, after acetone fractionation, was evaluated for three human cell lines: epithelial lung adenocarcinoma (A549), colon carcinoma (HCT-116) and Caucasian human glioblastoma (T98G). All 
of them were provided by the European Collection of Cell Culture (ECCC) and were tested by the Thiazolyl Blue Tetrazolium Bromide (MTT, Sigma) method [19]. The extracts of $H$. elongata and those obtained after acetone fractionation were tested at concentrations below $500 \mu \mathrm{g} / \mathrm{mL}$, Stauosporine (Biomar collection, AQUAe, Mérida, Spain) was used as a positive control, with IC $_{50}$ values against A549 cells $(0.001 \mu \mathrm{g} / \mathrm{mL})$, PSN1 cells $(0.001 \mu \mathrm{g} / \mathrm{mL})$, HCT-116 cells $(0.005 \mu \mathrm{g} / \mathrm{mL})$, and T98G cells $(0.001 \mu \mathrm{g} / \mathrm{mL})$, and as negative controls, the specific medium for each cell line without cells and untreated cells was used.

\subsection{Statistical Analysis}

All above experiments were performed at least in triplicate. Above data were assessed using one-factor analysis of variance, ANOVA. A post-hoc Scheffé test was performed to differentiate means with $95 \%$ confidence $(p<0.05)$ using the PASW Statistics v.22 software (IBM SPSS Statistics, New York, NY, USA).

\section{Conclusions}

To conclude, it should be indicated that acetone fractionation of sodium alginates recovered after subcritical water extraction of $H$. elongata is an adequate method to obtain a wide range of biopolymers with suitable extraction yields, different molecular mass distributions and block structures. The proposed processing conditions allow developing gelled matrices of intermediate strength with short maturation times, without jeopardizing thermal and viscoelastic stability. The absence of syneresis is another advantage of formulated gelled matrices. A slight impact of the extraction conditions on the cellular viability of tested epithelial lung adenocarcinoma, colon carcinoma and Caucasian human glioblastoma cell lines was observed.

Author Contributions: Conceptualization, M.D.T., N.F.-F. and H.D.; data curation, N.F.-F. and M.D.T.; writing—original draft preparation, N.F.-F. and M.D.T.; writing—review and editing, N.F.-F., M.D.T. and H.D.; funding acquisition, H.D. and M.D.T. All authors have read and agreed to the published version of the manuscript.

Funding: This research was funded by the Ministry of Economy and Competitiveness of Spain (CTM2015-68503-R). N.F.-F. thanks the Xunta de Galicia for her postdoctoral grant (ED481B 2018/071). M.D.T. thanks the Spanish Ministry of Economy and Competitiveness for her postdoctoral grant (RYC2018-024454-I) and Xunta de Galicia for the project (ED431F 2020/01).

Institutional Review Board Statement: Not applicable.

Informed Consent Statement: Not applicable.

Data Availability Statement: Data is contained within the article.

Conflicts of Interest: The authors declare no conflict of interest.

\section{References}

1. White, W.L.; Wilson, P. World Seaweed Utilization. In Seaweed Sustainability; Elsevier Inc.: Amsterdam, The Netherlands, 2015; ISBN 9780124186972.

2. Stiger-Pouvreau, V.; Bourgougnon, N.; Deslandes, E. Chapter 8-Carbohydrates from Seaweeds. In Seaweed in Health and Disease Prevention; Fleurence, J., Levine, I., Eds.; Academic Press: San Diego, CA, USA, 2016; pp. 223-274, ISBN 9780128027721.

3. Bixler, H.J.; Porse, H. A decade of change in the seaweed hydrocolloids industry. J. Appl. Phycol. 2011, 23, 321-335. [CrossRef]

4. Couteau, C.; Coiffard, L. Seaweed Application in Cosmetics. In Seaweed in Health and Disease Prevention; Elsevier Inc.: Amsterdam, The Netherlands, 2016; ISBN 9780128027936.

5. Kartik, A.; Akhil, D.; Lakshmi, D.; Panchamoorthy Gopinath, K.; Arun, J.; Sivaramakrishnan, R.; Pugazhendhi, A. A critical review on production of biopolymers from algae biomass and their applications. Bioresour. Technol. 2021, 329. [CrossRef] [PubMed]

6. Fleurence, J. Seaweeds as Food. In Seaweed in Health and Disease Prevention; Elsevier Inc.: Amsterdam, The Netherlands, 2016; ISBN 9780128027936.

7. Zhang, H.; Cheng, J.; Ao, Q. Preparation of alginate-based biomaterials and their applications in biomedicine. Mar. Drugs 2021, 19, 264. [CrossRef] [PubMed] 
8. Mahadevan, K. Seaweeds: A Sustainable Food Source; Elsevier Inc.: Amsterdam, The Netherlands, 2015; ISBN 9780124199583.

9. Acevedo-García, V.; Flórez-Fernández, N.; López-García, M.; Vilariño, J.M.L.; Domínguez, H.; Torres, M.D. Acetone Precipitation of Heterofucoidans from Sargassum muticum Autohydrolysis Extracts. Waste Biomass Valoriz. 2021, 12, 867-877. [CrossRef]

10. Déléris, P.; Nazih, H.; Bard, J.M. Seaweeds in Human Health. In Seaweed in Health and Disease Prevention; Elsevier Inc.: Amsterdam, The Netherlands, 2016; pp. 319-367, ISBN 9780128027936.

11. Gómez-Zorita, S.; González-Arceo, M.; Trepiana, J.; Eseberri, I.; Fernández-Quintela, A.; Milton-Laskibar, I.; Aguirre, L.; González, M.; Portillo, M.P. Anti-obesity effects of macroalgae. Nutrients 2020, 12, 2378. [CrossRef] [PubMed]

12. Garcia-Vaquero, M.; Lopez-Alonso, M.; Hayes, M. Assessment of the functional properties of protein extracted from the brown seaweed Himanthalia elongata (Linnaeus) S. F. Gray. Food Res. Int. 2017, 99, 971-978. [CrossRef] [PubMed]

13. Torres, M.D.; Flórez-Fernández, N.; Simón-Vázquez, R.; Giménez-Abián, J.F.; Díaz, J.F.; González-Fernández, A.; Domínguez, H. Fucoidans: The importance of processing on their anti-tumoral properties. Algal Res. 2020, 45, 101748. [CrossRef]

14. Zhu, B.; Ni, F.; Xiong, Q.; Yao, Z. Marine oligosaccharides originated from seaweeds: Source, preparation, structure, physiological activity and applications. Crit. Rev. Food Sci. Nutr. 2021, 61, 60-74. [CrossRef] [PubMed]

15. Liu, J.; Yang, S.; Li, X.; Yan, Q.; Reaney, M.J.T.; Jiang, Z. Alginate oligosaccharides: Production, biological activities, and potential applications. Compr. Rev. Food Sci. Food Saf. 2019, 18, 1859-1881. [CrossRef]

16. Ale, M.T.; Meyer, A.S. Fucoidans from brown seaweeds: An update on structures, extraction techniques and use of enzymes as tools for structural elucidation. RSC Adv. 2013, 3, 8131-8141. [CrossRef]

17. Reig-Vano, B.; Tylkowski, B.; Montané, X.; Giamberini, M. Alginate-based hydrogels for cancer therapy and research. Int. J. Biol. Macromol. 2021, 170, 424-436. [CrossRef]

18. Ahmad Raus, R.; Wan Nawawi, W.M.F.; Nasaruddin, R.R. Alginate and alginate composites for biomedical applications. Asian J. Pharm. Sci. 2021, 16, 280-306. [CrossRef]

19. Flórez-Fernández, N.; Torres, M.D.; González-Muñoz, M.J.; Domínguez, H. Recovery of bioactive and gelling extracts from edible brown seaweed Laminaria ochroleuca by non-isothermal autohydrolysis. Food Chem. 2019, 277, 353-361. [CrossRef]

20. Torres, M.D.; Kraan, S.; Domínguez, H. Seaweed biorefinery. Rev. Environ. Sci. Biotechnol. 2019, 18, 335-388. [CrossRef]

21. Xing, M.; Qi, C.; Yu, W.; Han, X.; Jiarui, Z.; Qing, Z.; Aiguo, J.; Shuliang, S. Advances in research on the bioactivity of alginate oligosaccharides. Mar. Drugs 2020, 18, 144. [CrossRef]

22. Cernadas, H.; Flórez-Fernández, N.; González-Muñoz, M.J.; Domínguez, H.; Torres, M.D. Retrieving of high-value biomolecules from edible Himanthalia elongata brown seaweed using hydrothermal processing. Food Bioprod. Process. 2019, 7, 275-286. [CrossRef]

23. Gómez-Ordóñez, E.; Alonso, E.; Rupérez, P. A simple ion chromatography method for inorganic anion analysis in edible seaweeds. Talanta 2010, 82, 1313-1317. [CrossRef] [PubMed]

24. Gómez-Ordóñez, E.; Jiménez-Escrig, A.; Rupérez, P. Dietary fibre and physicochemical properties of several edible seaweeds from the northwestern Spanish coast. Food Res. Int. 2010, 43, 2289-2294. [CrossRef]

25. Endo, H.; Suehiro, K.; Gao, X.; Agatsuma, Y. Interactive effects of elevated summer temperature, nutrient availability, and irradiance on growth and chemical compositions of juvenile kelp, Eisenia bicyclis. Phycol. Res. 2017, 65, 118-126. [CrossRef]

26. Flórez-Fernández, N.; Domínguez, H.; Torres, M.D. A green approach for alginate extraction from Sargassum muticum brown seaweed using ultrasound-assisted technique. Int. J. Biol. Macromol. 2019, 124, 451-459. [CrossRef] [PubMed]

27. Belattmania, Z.; Kaidi, S.; El Atouani, S.; Katif, C.; Bentiss, F.; Jama, C.; Reani, A.; Sabour, B.; Vasconcelos, V. Isolation and FTIR-ATR and $1 \mathrm{H}$ NMR characterization of alginates from the main alginophyte species of the atlantic coast of Morocco. Molecules 2020, 25, 433501. [CrossRef]

28. Fenoradosoa, T.A.; Ali, G.; Delattre, C.; Laroche, C.; Petit, E.; Wadouachi, A.; Michaud, P. Extraction and characterization of an alginate from the brown seaweed Sargassum turbinarioides Grunow. J. Appl. Phycol. 2010, 22, 131-137. [CrossRef]

29. Gómez-Ordóñez, E.; Rupérez, P. FTIR-ATR spectroscopy as a tool for polysaccharide identification in edible brown and red seaweeds. Food Hydrocoll. 2011, 25, 1514-1520. [CrossRef]

30. Mateos-Aparicio, I.; Martera, G.; Goñi, I.; Villanueva-Suárez, M.J.; Redondo-Cuenca, A. Chemical structure and molecular weight influence the in vitro fermentability of polysaccharide extracts from the edible seaweeds Himathalia elongata and Gigartina pistillata. Food Hydrocoll. 2018, 83, 348-354. [CrossRef]

31. Borazjani, N.J.; Tabarsa, M.; You, S.G.; Rezaei, M. Effects of extraction methods on molecular characteristics, antioxidant properties and immunomodulation of alginates from Sargassum angustifolium. Int. J. Biol. Macromol. 2017, 101, 703-711. [CrossRef] [PubMed]

32. Fertah, M.; Belfkira, A.; Dahmane, E.m.; Taourirte, M.; Brouillette, F. Extraction and characterization of sodium alginate from Moroccan Laminaria digitata brown seaweed. Arab. J. Chem. 2017, 10, S3707-S3714. [CrossRef]

33. Pereira, L.; Gheda, S.F.; Ribeiro-Claro, P.J.A. Analysis by vibrational spectroscopy of seaweed polysaccharides with potential use in food, pharmaceutical, and cosmetic industries. Int. J. Carbohydr. Chem. 2013, 2013, 537202. [CrossRef]

34. Fawzy, M.A.; Gomaa, M.; Hifney, A.F.; Abdel-Gawad, K.M. Optimization of alginate alkaline extraction technology from Sargassum latifolium and its potential antioxidant and emulsifying properties. Carbohydr. Polym. 2017, 157, 1903-1912. [CrossRef] [PubMed]

35. Sari-Chmayssem, N.; Taha, S.; Mawlawi, H.; Guégan, J.P.; Jeftić, J.; Benvegnu, T. Extracted and depolymerized alginates from brown algae Sargassum vulgare of Lebanese origin: Chemical, rheological, and antioxidant properties. J. Appl. Phycol. 2016, 28, 1915-1929. [CrossRef] 
36. Torres, M.D.; Raymundo, A.; Sousa, I. Effect of sucrose, stevia and xylitol on rheological properties of gels from blends of chestnut and rice flours. Carbohydr. Polym. 2013, 98, 249-256. [CrossRef] [PubMed]

37. García-Ríos, V.; Ríos-Leal, E.; Robledo, D.; Freile-Pelegrin, Y. Polysaccharides composition from tropical brown seaweeds. Phycol. Res. 2012, 60, 305-315. [CrossRef] 